\title{
Food allergy and anaphylaxis - 2065. Food- dependent exercise-induced anaphylaxis in a patient with sensitization to pork
}

\author{
Hyun Hee Lee ${ }^{1 *}$, Kyung Eun Lee ${ }^{2}$, Kyu-Earn Kim³ \\ From 2nd WAO International Scientific Conference (WISC 2012) \\ Hyderabad, India. 6-9 December 2012
}

\section{Background}

Food-dependent exercise-induced anaphylaxis (FDEIA) is a specific variant of exercise-induced anaphylaxis that requires both vigorous physical activity and the ingestion of specific foods. In particular, it is rare that FDEIA is associated with meat in Korea.

\section{Methods}

A 15-year-old female presented with generalised urticaria, dyspnea, severe cough, headache, dizziness, and vomiting after singing and dancing for 1 hour and after ingesting grilled pork. Serum specific IgE and skin prick tests were performed. Oral food challenge with boiled pork meat were done. We started boiled pork meat $10 \mathrm{~g}$ to $160 \mathrm{~g}$ every 30 mimutes. Exercise provocation test before and after pork ingestion were done.We did IgE immunoblotting with patient's serum by cooked (grilled, boiled) and raw pork allergen.

\section{Results}

Skin prick tests showed a strong positive reaction to pork, whereas the results of the oral food challenge and exercise provocation tests were negative. However, the exercise provocation test after pork ingestion showed a positive reaction manifested by generalized urticaria, cough, mild dyspnea, and $23 \%$ decreased peak expiratory flow rate. In IgE immunoblotting, 3 allergens of pork $(67 \mathrm{kDa}, 90 \mathrm{kDa}$, and $15 \mathrm{kDa}$ ) reacted with patient's serum by grilled pork allergen.

\section{Conclusion}

We report a case of pork-dependent exercise-induced anaphylaxis in a patient with sensitzation to pork. A patient was instructed to avoid exercise after pork meat ingestion in the future.

\section{Author details}

${ }^{1}$ Department of Pediatrics, Kwandong University College of Medicine, Goyang, South Korea. ${ }^{2}$ Department of Pediatrics and Institute of Allergy, Yonsei University College of Medicine, Seoul, South Korea. ${ }^{3}$ Yonsei University College of Medicine, South Korea.

Published: 23 April 2013

doi:10.1186/1939-4551-6-S1-P148

Cite this article as: Lee et al: Food allergy and anaphylaxis - 2065.

Food-dependent exercise-induced anaphylaxis in a patient with sensitization to pork. World Allergy Organization Journal 2013 6(Suppl 1): P148.
Submit your next manuscript to BioMed Central and take full advantage of:

- Convenient online submission

- Thorough peer review

- No space constraints or color figure charges

- Immediate publication on acceptance

- Inclusion in PubMed, CAS, Scopus and Google Scholar

- Research which is freely available for redistribution

\section{() Biomed Central}

\section{Ciomed Central}

